\title{
Gray Platelet Syndrome
}

National Cancer Institute

\section{Source}

National Cancer Institute. Gray Platelet Syndrome. NCI Thesaurus. Code C84741.

A rare inherited bleeding disorder characterized by the decrease or absence of the platelet alpha-granules and their proteins in the peripheral blood platelets. 